\title{
Structural Efficiency of Steel Stiffening Deck Systems in Suspension Bridges Due to Gravity Loads
}

\author{
Ahmed Gasim M. Hussein \\ ahmedgasim@gmail.com \\ Faculty of Engineering Sciences, Omdurman Islamic University, Omdurman, Sudan \\ Mohamed Faisal F. Mohamed \\ fadla faisal@hotmail.com \\ Faculty of Engineering Sciences, Ōmdurman Islamic University, Omdurman, Sudan
}

\begin{abstract}
In this paper, suspended stiffened decks in suspension bridges are considered. Three steel deck-stiffening systems are compared structurally; the plate girder, the box girder and the stiffening truss. A three-span continuous suspension bridge model is considered. Analysis is made by the second order non-linear deflection theory in its linearized form. Developed software is used for the analysis to determine the induced tension in the cable, moments, shears and deflections of the girders for any general live load case. AASHTO criteria for steel girders are adopted. AASHTO highway live loads -HL 93are applied to Khartoum-Tuti Suspension Bridge in Khartoum, Sudan for each type of the stiffening systems. Ten load cases are considered and discussed. Results have shown that the most efficient type to resist gravity loads is the stiffening truss, followed by the box girder and last is the plate girder.
\end{abstract}

Keywords: Suspension bridges; Steel deck systems; Deflection theory; AASHTO

\section{INTRODUCTION}

The principal structural elements of a three-span suspension bridge are as shown in Figure (1):

- Two or more high-strength steel main cables, and which support the traffic-carrying deck and transfer it's loading by direct tension forces to the supporting towers and anchorages.

- A deck structure together with a longitudinal stiffening system to distribute concentrated traffic loadings on the deck, and control local deflections. An economical overall design requires the lightest practicable deck structure which is supported from the main cables by hangers of high-strength wire ropes or strand that are spaced at regular intervals throughout the spans.

- Towers to support the main cables at a level determined by the main span cable sag

- Anchorages to secure the ends of the main cables against movement. 


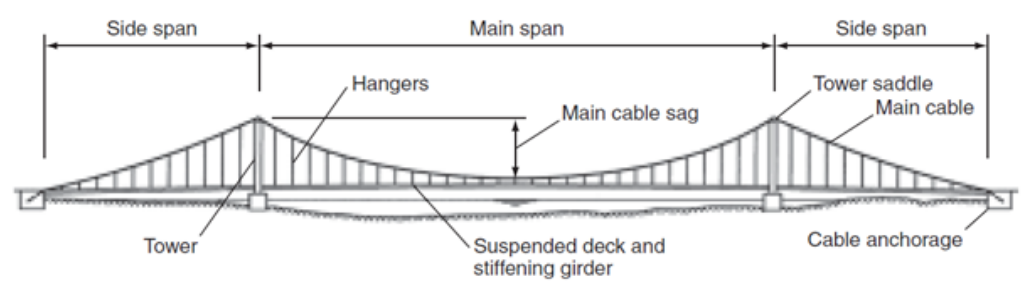

Figure 1: Suspension Bridge Elements. (Barker \& Pucket, 2007)

\section{REVIEW OF THEORIES OF ANALYSIS OF SUSPENSION BRIDGES:}

The different approaches that have been introduced for the analysis of externallyanchored

suspension bridges ( Pugsley, 1968; Arzoumanidis \& Bieniek, 1985;

Jennings, 1987 \& Hussein, 1998) can be summarized as follows:

i) The classical elastic theory: Derived on strain energy basis and yields higher bending moments and shears than the actual. The method is used for approximate analysis and preliminary designs.

ii) The deflection theory: Based on non- linear fourth order differential equation. The method is accurate but difficult to apply practically due to cumbersome work required to evaluate the solution parameters.

iii) The Linearized deflection theory: Based on the linearization of the basic differential equation of the deflection theory. The theory was treated in different ways such as the flexibility coefficient method, the Fourier series treatment, etc.... The method is less accurate than the deflection theory but permits the use of superposition and influence lines techniques.

iv) Matrix form solutions: In which the computer was used primarily. These solutions include the finite difference formulation; based on the Linearized deflection theory, and the finite element methods, based on the elastic stiffness of the members. These methods are easier but less accurate than the deflection theory.

In this research paper, a new treatment to the deflection theory will be introduced analytically and in computer form, yielding capability of solving any type of static loading. This, computerized treatment will be extended to the linearized deflection theory to make use of the superposition advantage.

\section{THE DEFLECTION THEORY AND ITS LINEARIZED FORM}

Steinman (1935), Pugsley (1968), Choi et al. (2013) and Hussein (1998)]

\subsection{Assumptions of the Deflection Theory}

a. Cable is parabola and sag span ratio is 1.8 or lesser.

b. Initial dead load is carried by the cable only, causing no stresses in stiffening deck.

c. Suspenders elongation are negligible, i.e. the girder vertical deflection at any point is the same as that of the corresponding point on the cable.

d. The deflection of any point on the cable, $\mathrm{v}(\mathrm{x})$, due to applied live load "P" per unit length of girder, is sensible compared with the initial dead load ordinate $y(x)$ of that point. 


\subsection{Fundamental Equations of the Deflection Theory}

If the distortion of structural geometry of the span of a suspension bridge under the action of live loads is neglected, and if $y$ describes the cable ordinate from the horizontal line joining the two towers, the bending moment at any point of a simple suspended span, $M$ is given by the basic formula of the elastic theory (Pugsley, 1968) See Figure (2).

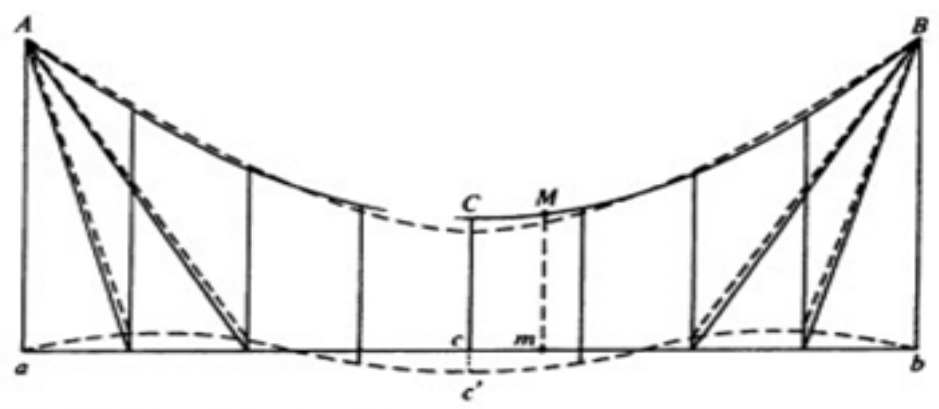

Figure 2: Elastic Theory

$$
M=M_{0}-h y
$$

Due to the fact that distortions might be very large, especially for long spans, the deflection theory accounts for the effects of these changes in geometry. For amount of deflection $\mathrm{v}$, the bending moment will be reduced to

$$
M=\left[M_{0}-h y\right]-(H+h) v
$$

Where $M_{0}$ is the dead load Moment; $\mathrm{h}$ and $\mathrm{H}$ is the horizontal components of cable tension due to live and dead loads respectively.

For continuous suspended middle span, accounting for continuity moment at the tower $T$, equation (2) will take the form

$$
M=\left[M_{0}-h y\right]-(H+h) v+T
$$

From Euler's equation for flexure

$$
M=-E I v^{\prime \prime}
$$

The following equation, eq. (5), called the fundamental equation of the girder is describing the deflection of

the girders according to the deflection theory

$$
v^{\mathrm{s}}=C^{2} v-\frac{C^{2}}{H+h}\left(M_{0}+T-h\right)
$$




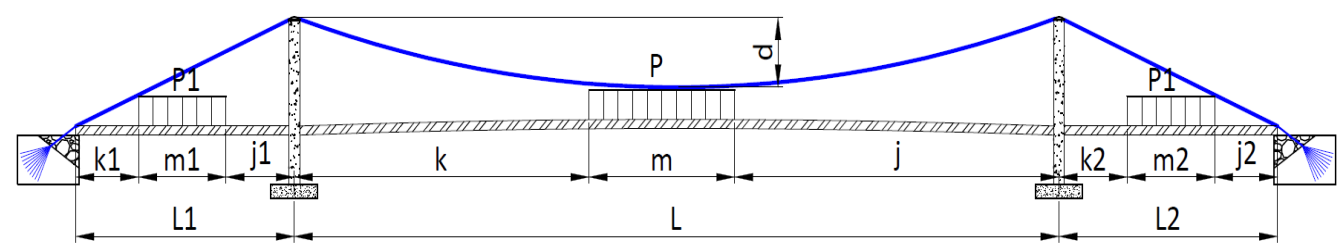

Figure 3: Deflection Theory Parameters for 3-Spans symmetrical Suspension Bridge

The nonlinear differential equation (5) can be solved as follow:

$$
v=\frac{h}{h+H}\left\{C_{1} e^{C X}+C_{2} e^{C X}+\left[\frac{M_{0}}{h}+\frac{T}{h}-y\right]+\frac{1}{C^{2}}\left(\frac{8 d}{L^{2}}-\frac{P}{h}\right)\right\}
$$

It can be shown that:

$$
H=\frac{w l^{2}}{8 d}
$$

Where $w$ is the total dead load per unit length of cable; and

$$
C^{2}=\frac{H+h}{E I}
$$

The coefficients $\mathrm{C}_{1} \& \mathrm{C}_{2}$ can be obtained from the boundary conditions. The effect of continuity moment $\mathrm{T}$ can be obtained by

$$
T=T_{1}-\left(T_{1}+T_{2}\right) \frac{x}{l}
$$

Where the girder continuity momehts at the left and right towers, $T_{1} \& T_{2}$, are evaluated by equating slopes at the towers.

Equation (6) is the first fundamental equation; known as the girder equation. There are two unknowns; namely the deflection $v$ and the induced tension " $h$ ". The other fundamental equation, known as the cable equation, is:

$$
\frac{h l}{A_{c} E_{c}} \pm \propto L_{c} t-\frac{w}{H} \int_{0}^{L} v d x=0
$$

in which $l$ is the horizontal projection of cable length $L_{c}, \alpha$ is the coefficient of linear thermal

expansion, $t$ is the temperature difference, $\theta$ is the cable inclination, $A_{c}$ is the cable x-sectional area, $E_{c}$ is the cables' modulus of elasticity, and

$$
\begin{aligned}
& l=\int_{0}^{L}\left(\frac{d s}{d x}\right)^{3} d x \approx L\left(\sec ^{3} \theta+8 \frac{d^{2}}{L^{2}} \sec \theta\right) \\
& L_{c}=\int_{0}^{L}\left(\frac{d s}{d x}\right)^{2} d x \approx L\left(\sec ^{2} \theta+\frac{16}{3} \frac{d^{2}}{L^{2}}\right)
\end{aligned}
$$


The cable equation is derived in detail and the solution of equation (5) are as shown by Hussein (1998), yielding the general formula for deflection of the girder or truss

$$
v=\frac{h}{h+H}\left[C_{1} e^{C x}+C_{2} e^{-C x}+\left(\frac{M_{0}}{h}+\frac{T}{h}-y\right)+\frac{1}{C^{2}}\left(\frac{8 d}{L^{2}}-\frac{p}{h}\right)\right]
$$

Where $\mathrm{p}$ is the intensity of the live load at the section, $\mathrm{x}$, and $\mathrm{C}_{1}$ and $\mathrm{C}_{2}$ are integration constants; and all other symbols are as defined previously.

\subsection{The Linearized Deflection Theory}

The only different assumption of the linearized deflection theory from those of the deflection theory is that: since the live load $\mathrm{p}$ is small as compared to the dead load $\mathrm{w}$, then $\mathrm{h}$ is small as compared to $\mathrm{H}$, and accordingly, the term $(\mathrm{H}+\mathrm{h})$ in the first fundamental equation of the deflection theory, can be replaced only by $\mathrm{H}$. This will yield the general solution to be:

$$
v=\frac{h}{H}\left[C_{1} e^{C x}+C_{2} e^{-C x}+\frac{M_{0}}{h}+\frac{T}{h}-y+\frac{1}{C^{2}}\left(\frac{8 d}{L^{2}}-\frac{p}{h}\right)\right]
$$

\section{i.1 Developed Algorithm:}

The solution above has been put in a general form to enable applying any gravity load case as shown in Figure (3). The steps to solve for any loading case are as follows:

1. Enter bridge data: L, L1, I etc.

2. Enter load data: $\mathrm{p}, \mathrm{p}_{1}, \mathrm{p}_{2}, \mathrm{k}, \mathrm{m}$, etc.

3. Assume initial values for the main span continuity moments as $T_{1}=T M 1$ and $T_{2}=T M 2$.

4. Assume an initial value for the induced tension $h=h^{(1)}$.

5. Calculate integration constants $\mathrm{C}_{1} \& \mathrm{C}_{2}$ corresponding to all bridge loaded \& unloaded segments.

6. Calculate an improved value of $\mathrm{h}=\mathrm{h}^{(2)}$.

7. Go back to step (4) using $\mathrm{h}^{(2)}$ as $\mathrm{h}^{(1)}$ and repeat the procedure till convergence, i.e. $\mathrm{h}^{(\mathrm{i})}=\mathrm{h}^{(\mathrm{i}-1)}=\mathrm{h}^{\mathrm{f}}$

8. For the assumed pair (TMI, TM2), and using the last computed value of $\mathrm{h}=\mathrm{h}^{\mathrm{f}}$ in step (7), compute the corresponding values of integration constants $\mathrm{C}_{1} \& \mathrm{C}_{2}$, and then calculate new values of continuity moments TN1\&TN2.

9. Check if $\mathrm{TN} 1=\mathrm{TM} 1 \& \mathrm{TN} 2=\mathrm{TM} 2$. If not, go back to step (3) assuming another initial set of continuity moments, and repeat the procedure till convergence; i.e. $\mathrm{TN} 1=\mathrm{TM} 1 \& \mathrm{TN} 2=\mathrm{TM} 2$.

10. The last set of values: $h^{f}, T N 1 \&$ TN2 of step (9) represent the correct values. Use these values then to compute moments, shears, deflections and suspender tensions.

\section{KHARTOUM-TUTI SUSPENSION BRIDGE CASE STUDY WITH VARIOUS STEEL DECK SYSTEMS}

In this section the developed software based on the linearized deflection theory will 
be applied to Khartoum - Tuti Suspension Bridge in Sudan. Three steel deck systems will be used for the analysis, the existing plate girder system, a proposed box girder system equivalent in area to that of the original plate girder, and a stiffening truss system equivalent in area to the other alternatives. AASHTO criteria for each system is checked, and AASHTO (HL 93) live load will be applied to the bridge for different load cases as shown.

\subsection{Tuti Suspension Bridge with its original plate girder system}

4.1.1 Bridge Data; (Dorman Long Technology (2007))

With the reference of the parameters in Fig. (3):

$\mathrm{L} 1=50 \mathrm{~m}, \mathrm{~L}=210 \mathrm{~m}, \mathrm{D}=25 \mathrm{~m}, \mathrm{~W}=130 \mathrm{kN} / \mathrm{m}$

Modulus of Elasticity for the steel $=200 \times 10^{6} \mathrm{kN} / \mathrm{m}^{2}$

Cable Inclination angle at the tower $=20.8^{\circ}$, Camber $(\mathrm{CM})=1.5 \mathrm{~m}$

Thermal Expansion Coeficient $=11.7 \times 10^{-6} /{ }^{\circ} \mathrm{C}$

Plate girder $\mathrm{x}$-sectional Area $=0.1588 \mathrm{~m}^{2}$ (see Figure 4), $\mathrm{A}=0.1588 \mathrm{~m}^{2} \quad \mathrm{Ixx}=0.1257 \mathrm{~m}^{4}$

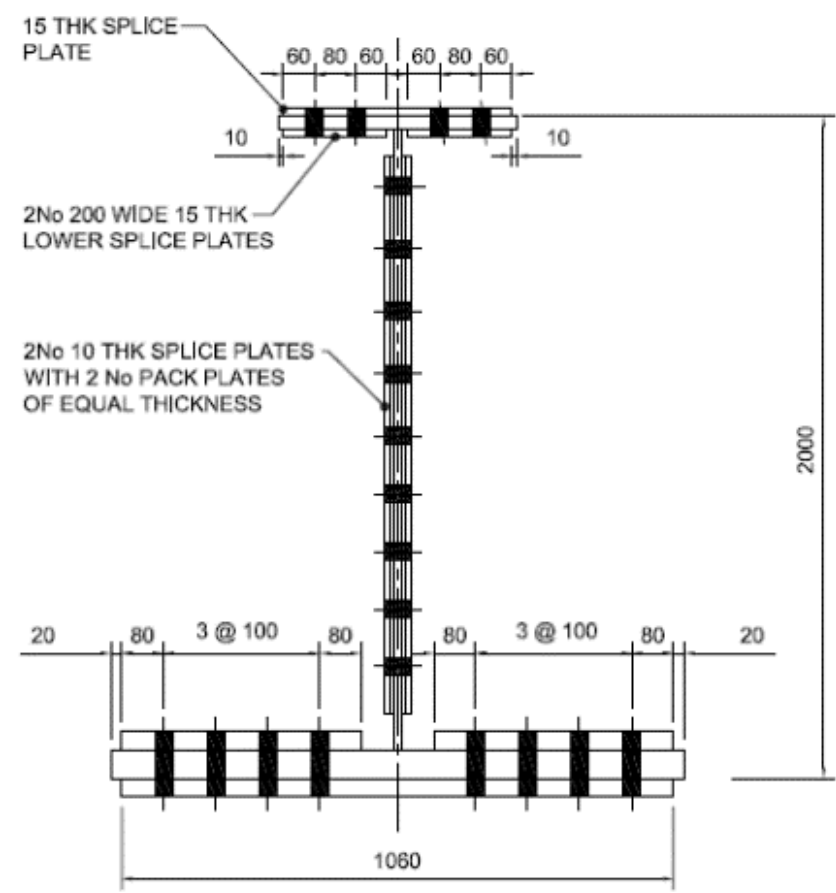

Figure 4: X-section of Tuti Br. Plate Girder

\subsubsection{AASHTO requirements for Plate Girders}

This as AASHTO (2012) section (6.7.3) states:

"Structural steel, shall not be less than $8.0 \mathrm{~mm}$, in thickness". Also as AASHTO section (6.10.2), for I section (rolled and plate girder), for webs without longitudinal stiffeners: $\frac{D}{t_{w}} \leq 150$ and for webs with longitudinal stiffeners: $\frac{D}{t_{w}} \leq 300$ ) compression and tension flanges shall be proportioned to: $\frac{b_{f}}{2 t_{f}} \leq 1 ; b_{f} \geq \frac{D}{6}, t_{f} \geq 1.1 t_{w} ; 0.1 \leq \frac{l_{y c}}{l_{y t}} \leq 1.0$ 


\subsection{Tuti Suspension Bridge with box girder system}

\subsubsection{Selected Box Girder section (see Figure 5)}

$\mathrm{A}=0.159 \mathrm{~m}^{2}, \quad \mathrm{I}_{\mathrm{XX}}=0.1571 \mathrm{~m}^{4}, \quad \mathrm{I}_{\mathrm{YY}}=0.0433 \mathrm{~m}^{4}$

Check:

$\frac{D}{t_{w}} \leq 150, \frac{D}{t_{w}}=\frac{2.7}{0.02}=135 \leq 150 \mathrm{OK}$

$b_{f} \geq \frac{D}{6} \frac{D}{6}=\frac{2.7}{6}=0.45$ $1.2 \geq 0.45 \mathrm{OK}$

And:

$t_{f} \geq 1.1 t_{w} 1.1 t_{w}=1.1 \times 0.02=0.022 \mathrm{OK}$

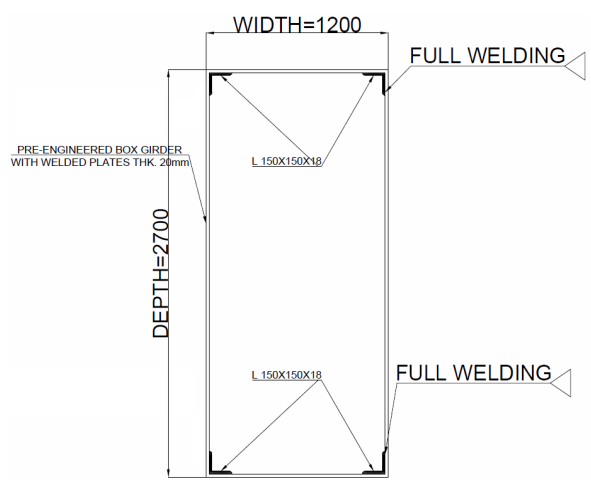

Figure 5: Proposed Box Girder

\subsubsection{AASHTO requirements for Box Sections}

As per AASHTO (2012) section (6.11.2), Webs without longitudinal stiffeners shall be proportioned such that:

$\frac{D}{t_{w}} \leq 150$; And for webs with longitudinal stiffeners: $\frac{D}{t_{w}} \leq 300$

The flanges of tub sections subjected to compression or tension shall be proportioned such

That: $\quad b_{f} \geq \frac{D}{6} ; \quad$ And $\quad t_{f} \geq 1.1 t_{w}$

\subsection{Tuti Suspension Bridge with Stiffening Truss system}

\subsubsection{Selected Truss section (see Fig. 6)}

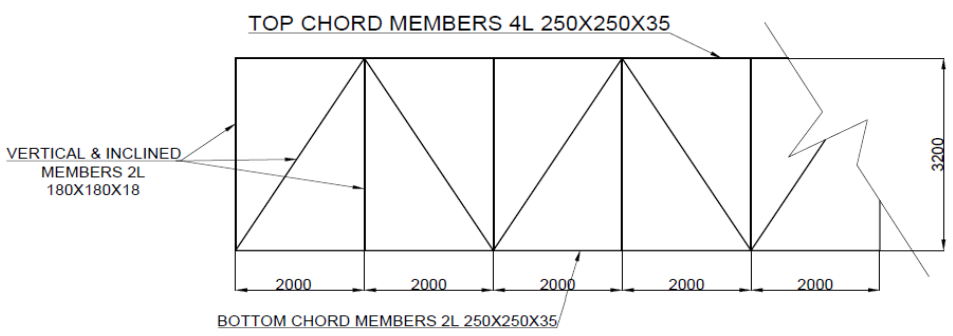

Figure 6: Proposed Stiffening Truss

The calculated section properties are as follows: $A=0.14 \mathrm{~m}^{2} \quad \mathrm{Ixx}=0.41 \mathrm{~m}^{4}$ 


\subsubsection{AASHTO requirements for Trusses}

As described in AASHTO (2012) section (6.14.2) Trusses should have inclined end posts. Effective depths of the truss shall be assumed as follows:

- The distance between centers of gravity of bolted chords, and

- The distance between centers of pins.

- Members shall be symmetrical about the central plane of the truss.

5 LIVE LOAD CASES: (As shown in Fig. 7)

\begin{tabular}{|c|c|c|}
\hline \multirow{3}{*}{$\begin{array}{l}\text { CASE (1) } \\
\text { LANE }\end{array}$} & \multicolumn{2}{|l|}{ CASE FULL } \\
\hline & \multicolumn{2}{|c|}{ 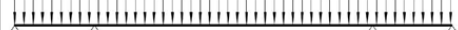 } \\
\hline & म & 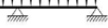 \\
\hline \multirow{3}{*}{$\begin{array}{l}\text { CASE (2) } \\
\text { LANE }\end{array}$} & \multicolumn{2}{|l|}{ MAX.+VE MOMENTS@ @IDE SPANS } \\
\hline & $\omega \cdots \cdots$ & 11111111 \\
\hline & मालो & $\Rightarrow$ \\
\hline \multirow{3}{*}{$\begin{array}{l}\text { CASE (3) } \\
\text { LANE }\end{array}$} & \multicolumn{2}{|l|}{ MAX.+VE MOMENTS@ MAIN SPAN } \\
\hline & \multicolumn{2}{|c|}{ 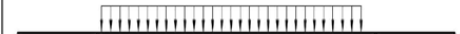 } \\
\hline & 两 & 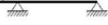 \\
\hline \multirow{3}{*}{$\frac{\text { CASE (4) }}{\text { TRUCK }}$} & \multicolumn{2}{|l|}{ MAX.+VE MOMENTS @.MAIN SPAN } \\
\hline & \multicolumn{2}{|l|}{ III } \\
\hline & 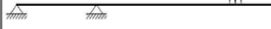 & 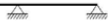 \\
\hline \multirow{3}{*}{$\frac{\operatorname{CASE}(5)}{\underline{\text { TRUCK }}}$} & \multicolumn{2}{|l|}{ MAX.+VE MOMENTS@ @IDE SPANS } \\
\hline & III & III \\
\hline & $\mathrm{Am}$ & Aो \\
\hline
\end{tabular}

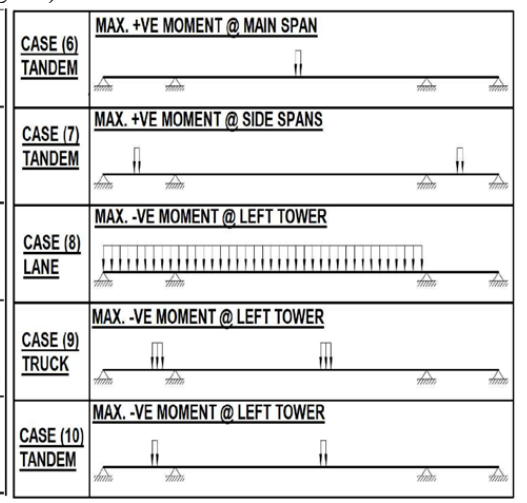

Figure 7: All Live Load Cases

\section{RESULTS AND DISCUSSION}

The results obtained -as in Figures 8, 9 and 10- shows clearly that for the different load cases considered the minimal deflections are obtained when using the stiffening truss choice, followed by the box girder and then the plate girder with maximum deflections. For maximum bending moments, although the truss is not the optimum but due to its larger depth the bending stresses in the top and bottom chords are far low from limiting stresses. Fabrication difficulties encountered in trusses can be minimized by making use of new technologies. It is clear that this comparison is for gravity loads only, and assuming one stiffening member per each cable.

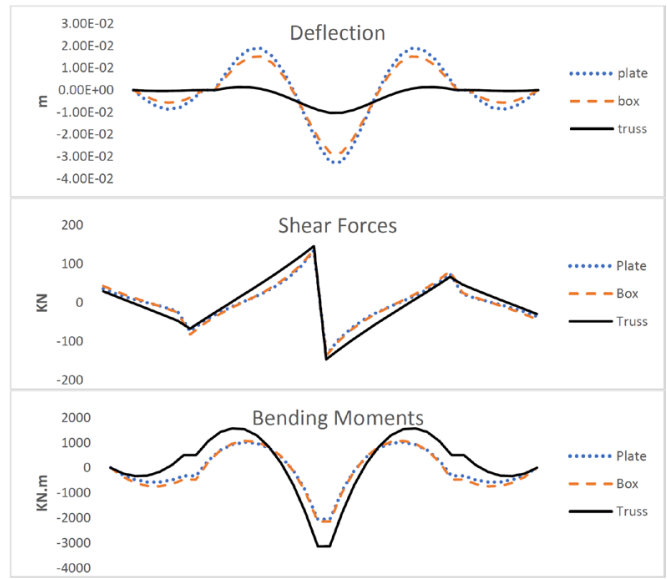

Figure 8: Results of Analysis of Tuti Suspension Bridge for load case (4) 


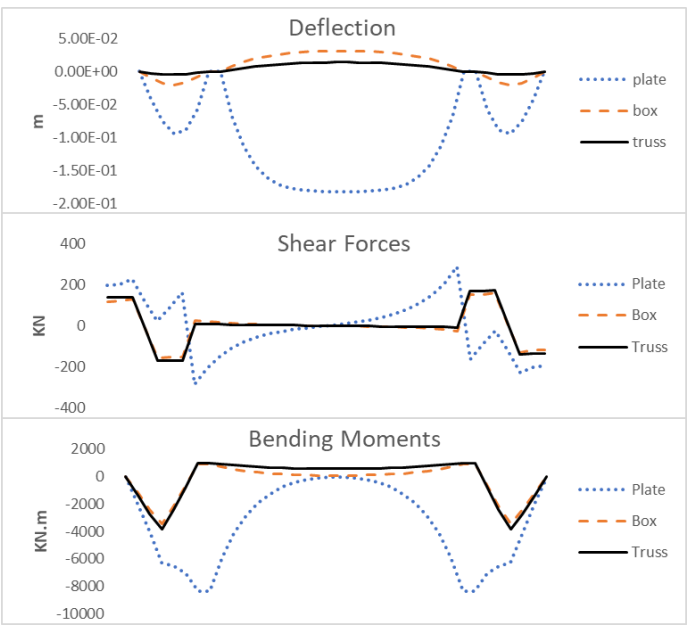

Figure 9: Results of Analysis of Tuti Suspension Bridge for load case (5)

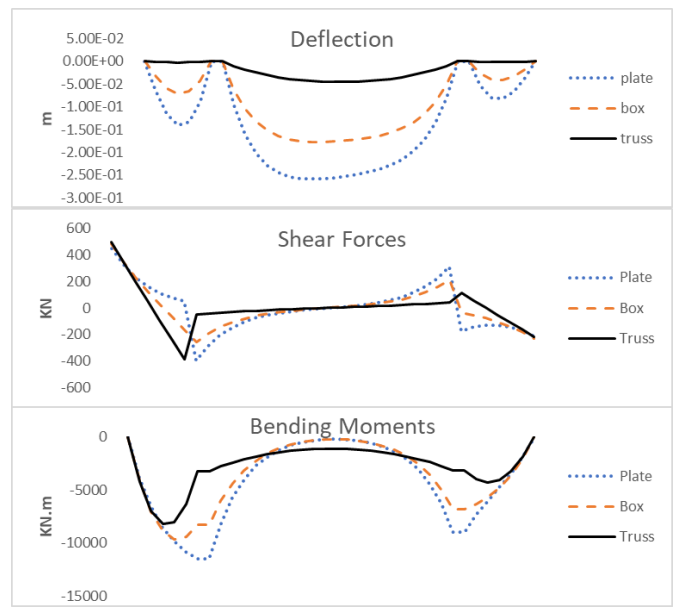

Figure 10: Results of Analysis of Tuti Suspension Bridge for load case (8)

\section{CONCLUSION}

For the three selected steel deck-stiffening systems to suspension bridge decks, the stiffening truss has been the optimum, structurally to resist gravity loads. The box girder is found to be the second and the plate girder system to be the third. Of course, the optimum deck choice has to consider other loads than gravity ones; like dynamic wind and earthquake loads.

\section{REFERENCES}

American Association of State and Highway Transportation Officials (2012). AASHTO LRFD Bridge Design Specifications, Chapter 6, AASHTO Executive Office, Washington, D.C.

Arzoumanidis, S. G. \& Bieniek (1985) M. P. Finite Element Analysis of Suspension Bridges.

Computers \& structures, Vol. 21, No. 6, PP 1237-1253.

Barker, R. M. \& Puckett, J. A. (2007). Design of Highway Bridges an LRFD Approach. John 
Wiley \& Sons, Inc., New Jersey.

Choi, D., Gwon, S. \& Yoo, H. (2013). Nonlinear static analysis of continuous multi-span suspension bridges. Int. J. Steel Struct, 13(1), 103-115.

Dorman Long Technology (2007). Khartoum-Tuti Suspension Bridge Design Drawings. London.

Hussein, Ahmed G. (1998). Static and Free Vibration Analysis of Suspension Bridges (Ph.D. Thesis to Baghdad University). Baghdad.

Jennings, A. (1987) Deflection Theory Analysis of Different Cable Profiles for Suspension Bridges. Engineering structures, V. 9, No.2, April 1987, P (84-94).

Pugsley, Sir Alfred (1968). The Theory of Suspension Bridges. Edward Arnold, 2nd ed. 1968.

Shin, S., Jung. M., Park, J. \& Kim, M. (2013). A deflection theory and its validation of earthanchored suspension bridges under live loads. KSCE J.

Steinman, D. B. (1935). A Generalized Deflection Theory for Suspension Bridges; Transactions, ASCE, Vol.100, 1935, P (1113-1170). 